\title{
The ameliorative impacts of curcumin on copper oxychloride-induced hepatotoxicity in rats
}

\author{
Heba N. Gad El-Hak (1D and Yomn M. Mobarak
}

\begin{abstract}
Background: Copper oxychloride (COC) (50\% of its component, copper) is copper-based fungicides. The present study aimed to investigate the possible protective effect of $80 \mathrm{mg} / \mathrm{kg}$ curcumin against the toxicity of 500, 1000, or 2000 mg COC per kilogram body weight for 90 days on the liver of a rat. Serum glutamic-pyruvic transaminase (SGPT), serum glutamic-oxaloacetic transaminase (SGOT), hepatic glutathione reduced content (GSH), and malondialdehyde (MDA) levels were detected. The histological and ultrastructure changes of the liver tissues as well as the hepatic content of copper, iron, manganese, and zinc were also reported.

Results: COC-treated rats showed an increase of SGPT and SGOT, with the elevation of copper and zinc content and MDA levels with no change in GSH level. The liver showed a significant increase in the copper and iron contents. The liver of COC-treated rats showed histological and ultrastructural damage that increased with increasing the COC dose. Conversely, curcumin supplementation potentially recovered liver function enzymes in only low doses of COC, reduced MDA level, increased GSH content, and improved the hepatic lesions. These findings revealed that subchronic exposure to even low levels of COC may have potential hazards and harmful effects on the liver, and the curcumin markedly attenuated the COC biochemical, histological, and cellular alterations in liver tissues, best with the low dose of COC.
\end{abstract}

Conclusions: It is concluded that curcumin has a limited protective role against COC liver toxicity.

Keywords: Copper oxychloride, Curcumin, Liver enzyme, Liver histology, Liver ultrastructure

\section{Background}

The copper oxychloride is a fungicide that specifically inhibits or kill fungi underlying diseases for keeping of consuming vegetables and fruits fresh for long periods in supermarkets (Osman et al. 2011). Hence, consumers and farm workers can be exposed to the fungicide residues in food and water during oral, inhalation, and dermal application (Damalas and Eleftherohorinos 2011). Understanding the mechanisms of fungicide action and toxicity is significant because humans encounter these pesticides through a broad assortment of applications (Kim et al. 2017).

The liver is the major organ responsible for metabolism, detoxification, and secretory functions in the body

\footnotetext{
* Correspondence: heba_nageh@hotmail.com

Zoology Department, Faculty of Science, Suez Canal University, Ismailia, Egypt
}

(c) The Author(s). 2018 Open Access This article is distributed under the terms of the Creative Commons Attribution 4.0 International License (http://creativecommons.org/licenses/by/4.0/), which permits unrestricted use, distribution, and reproduction in any medium, provided you give appropriate credit to the original author(s) and the source, provide a link to the Creative Commons license, and indicate if changes were made.

(Gebhardt 1992). Hence, it regulates various important metabolic functions in mammalian systems. Hepatic damage is associated with the distortion of these metabolic functions (Wu 2009). Copper is a micronutrient essential for life; copper follows a specific homeostatic regulation mechanism, which allows excess copper to be excreted mainly through the bile. Copper is absorbed, transported, distributed, stored, and excreted in the body according to complex homeostatic processes which ensure a constant and sufficient supply of the micronutrient while simultaneously avoiding excess levels (Husak 2015). Target organs of excess copper after oral administration are the liver and the kidneys.

Curcumin (1, 7-bis (4-hydroxy-3-methoxyphenyl)-1, 6-heptadiene-3, 5-dione) is a group of phenolic compounds isolated from the roots of Curcuma longa (Zingiberaceae) and has long been used as a spice in Indian dishes and as a drug in the traditional Indian
Springer Open

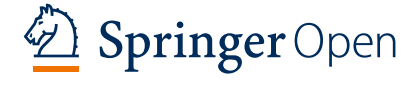


system of medicine that helps in preventing certain diseases. The active portion of curcumin is turmeric, has been shown to have significant antioxidant activity, both in vitro and in vivo (Joe et al. 2004) with the responsibility of $\mathrm{H}$-atom donation from the phenolic group (Jovanovic et al. 1999). Curcumin is a potent scavenger of reactive oxygen and nitrogen species (Reddy and Lokesh 1996) and protects biomembranes against peroxidative damage (Gao et al. 2013; Priyadarsini 1997). The antioxidant activity has been proven to have an important role in the regulation of physiological and pathological process by contribution in the protection of cells and tissues against deleterious effects of reactive oxygen species and other free radicals (Otuechere et al. 2014). Curcumin has been used for the treatment and protection of liver disorder in many research (Bruck et al. 2007; Farombi et al. 2008; Fu et al. 2008; García-Niño and Pedraza-Chaverrí 2014; Girish et al. 2009; Girish and Pradhan 2012; Manjunatha and Srinivasan 2006; Naik et al. 2004; Naik et al. 2011; Nanji et al. 2003; Park et al. 2000; Shen et al. 2007; Yousef et al. 2010).

Keeping this in view, the purpose of this investigation is to develop a biochemical, histological, and cellular study about the potential hepatotoxic effect of subchronic copper oxychloride treatment and the possible protective role of curcumin to modulate these effects in male albino rats.

\section{Materials and methods \\ Chemicals}

The commercial copper oxychloride contains $55 \%$ of its weight copper. It is a light green, very fine, nonfree-flowing powder containing soft aggregates. It had been equipped from the central agricultural pesticide laboratory, ARC, Egypt. Corn oil solution of copper oxychloride of the required concentration (500, 1000, and $2000 \mathrm{mg} / \mathrm{kg}$ body weight) was prepared and administered orally to rats $(0.5 \mathrm{ml} / \mathrm{rat} /$ day $)$. The selected doses were selected according to the detected $\mathrm{LD}_{50}$ of copper oxychloride to a rat which was $5000 \mathrm{mg} / \mathrm{kg}$ body weight.

Curcumin was purchased in a powder form from Sigma chemical company, Egypt. Corn oil solution of whole curcumin of the required concentration $(80 \mathrm{mg} /$ $\mathrm{kg}$ body weight) was prepared and administered orally to rats $(0.5 \mathrm{ml} / \mathrm{rat} /$ day) (Hashish and Elgaml 2016).

\section{Animals}

For this study, 54 adult male albino rats (Rattus norvegicus) (9-week-old, weighing 120-150 g) were purchased from the animal house, National Research Center, Cairo, Egypt. For adjustment, all rats were kept for a week under our laboratory conditions and were fed with pelleted food and tap water ad libitum. They were treated in accordance with the principles of Laboratory Animal
Facilities (Council 2010). The rats were put in cages made of stainless steel in a temperature-controlled room $\left(24 \pm 2{ }^{\circ} \mathrm{C}\right)$ with a 12 -h light and 12-h dull exposures. All rats were prevented of food and water $60 \mathrm{~min}$ before the start of the experiments.

\section{Experimental design}

The male rats were divided into nine groups, each consisting of six rats. The first group (control) was kept with none treatment, whereas the second group (oil) received orally $0.5 \mathrm{ml}$ of corn oil by gastric tube. The third group (COC LD) was treated orally by a gastric tube with COC at daily doses of $500 \mathrm{mg} / \mathrm{kg}$ body weight. for 90 days, the fourth group (COC MD) was treated orally by a gastric tube with COC at daily doses of $1000 \mathrm{mg} / \mathrm{kg}$ body weight for 90 days, and the fifth group (COC HD) was treated orally by a gastric tube with COC at daily doses of $2000 \mathrm{mg} / \mathrm{kg}$ body weight for 90 days. The sixth group (curcumin) were treated with $80 \mathrm{mg} / \mathrm{kg} /$ rat curcumin for 90 days. The seventh group (COC LD + Curcumin) were treated with $80 \mathrm{mg} / \mathrm{kg} / \mathrm{rat}$ curcumin additionally to $500 \mathrm{mg} / \mathrm{kg}$ COC by oral tube diluted with $0.5 \mathrm{ml}$ corn oil for 90 days. The eighth group (COC MD + Curcumin) were treated with $80 \mathrm{mg} / \mathrm{kg} / \mathrm{rat}$ curcumin additionally to $1000 \mathrm{mg} / \mathrm{kg} \mathrm{COC}$ by oral tube diluted with $0.5 \mathrm{ml}$ corn oil for 90 days. The ninth group (COC HD + Curcumin) were treated with $80 \mathrm{mg} / \mathrm{kg} /$ rat curcumin additionally to $2000 \mathrm{mg} / \mathrm{kg}$ COC by oral tube diluted with $0.5 \mathrm{ml}$ corn oil for 90 days.

\section{Bioassay}

At the end of the treatment period, the rats were anesthetized using chloroform according to Saleem et al. (2017) using the guide and care of using experimental animals (Olfert et al. 1993); blood samples were collected to measure the blood serum biochemical parameters from the retro-orbital blood vessel of all the rats according to Hui et al. (2007). The blood serum obtained after centrifugation (3000 rpm for $10 \mathrm{~min}$ at $4{ }^{\circ} \mathrm{C}$ ) was used for varied biochemical assays. Following the collection of blood samples, all experimental and control groups were sacrificed $24 \mathrm{~h}$ after the last dose by cervical dislocation, and therefore, the liver from every rat was removed and washed with saline solution. All the enzyme analyses were done among 1 week of collecting the samples. One gram from liver tissue samples was instantly frozen and hold on at $-40{ }^{\circ} \mathrm{C}$ for the next estimation of MDA, GSH, and determination of element (copper, iron, manganese, and zinc) within the liver. The other liver tissue specimens were kept in appropriate fixatives for the histopathological examination and therefore the ultrastructure study. 


\section{Biochemical analysis}

The activities of serum glutamic-pyruvic transaminase (SGPT) and serum glutamic-oxaloacetic transaminase (SGOT) were determined by the colorimetric technique of Reitman and Frankel (1957) using an assay kit. The lipid peroxidation level biomarker in the liver was estimated by the thiobarbituric acid technique and measured according to Ohkawa et al. (1979), and GSH was measured in the liver according to Hissin and Hilf (1976) using commercial kits instructions. Copper, zinc, iron, and manganese concentrations in liver tissues were measured by atomic absorption spectrophotometry by digestion with a combination of nitric acid and perchloric acid $(6: 1, v / v)$, and also, the digestion was delivered to constant volume with double distilled deionized water (Luterotti and Juretić 1992).

\section{Histopathological study}

Liver tissues of treated and control rats were fixed with $10 \%$ neutral buffered formalin solution. The fixed specimens were cut, washed, dehydrated in ascending grades of ethyl alcohol $(70 \%, 80 \%, 90 \%, 95 \%$, and $100 \%)$, cleared in xylene, embedded in paraffin $\left(60{ }^{\circ} \mathrm{C}\right.$ melting point) then sectioned $(4-6 \mu \mathrm{m})$, and stained with hematoxylin and eosin (Fischer et al. 2008) or stained with Masson trichrome (Goldner 1938) for histomorphological examine and sectioned for immunohistochemical determination of caspase 3 expression (Key 2006).

\section{Ultrastructure study (transmission electron microscopy)}

A small piece of liver was excised and then cut below a dissecting microscope in the presence of $2 \%$ glutaraldehyde. Liver specimens were immersed in $2 \%$ glutaraldehyde fixative in $0.1 \mathrm{M} \mathrm{Na}$-cacodylate buffer for $24 \mathrm{~h}$, then washed in $0.1 \mathrm{M}$ phosphate buffer at $4{ }^{\circ} \mathrm{C}$ and post-fixed in $1 \%$ osmium tetraoxide. After dehydration in a graduated series of ethyl alcohol, the tissues were infiltrated in resin. Blocks with tissues were cut into semi-thin sections, then stained with toluidine blue and examined using a light microscope. Representative fields of semi-thin sections were selected. Ultrathin sections were stained with uranyl acetate and lead citrate (Sato et al. 2008) and examined with transmission electron microscope (JEOLJEM-2100, Japan) within the Electron Microscope Unit, Faculty of Agriculture, Mansoura University, Mansoura, Egypt.

\section{Statistical analysis}

Data were analyzed using SPSS version 17.0 for Windows. All values given within the text were expressed as mean \pm standard error (SEM). One-way analysis of variance (ANOVA) test was used to compare the differences between the groups followed by post hoc Duncans multiple range test. Test $p \leq 0.05$ was considered significant.

\section{Results}

Effects of $\mathrm{COC}$ and curcumin on serum enzyme levels The results of SGPT and SGOT activities in liver tissues of all groups are listed in Table 1. Treatments with curcumin alone and corn oil did not change the activities of SGPT and SGOT as compared to the control group. There was a hepatotoxicity after 500, 1000, and $2000 \mathrm{mg} / \mathrm{kg}$ body weight with $\mathrm{COC}$ treatments for 90 days, as evidenced by significant increases $(p<0.05, p<0.05)$ in SGPT and SGOT levels compared to control rats. The higher dose treatment with COC induced higher significant $(p<0.05)$ levels of serum liver biomarker enzymes SGPT and SGOT than controls. Curcumin and oil group exhibited similar effects on serum biochemical parameters when compared with controls. COC LD + Curcmin group had significantly $(p<0.05)$ reduced SGPT and SGOT activities compared to the COC LD group.

\section{Effects of $\mathrm{COC}$ and curcumin on liver GSH reduced and MDA levels in rats}

Results indicated that COC MD and COC HD demonstrated a marked increase of hepatic MDA levels and non-significant change to the GSH levels compared to the control group $(p<0.005)$. COC LD + Curcmin group altered the above changes by regulating the MDA level and GSH to nearly that of the control. Curcumin only and corn oil administered alone did not alter the lipid peroxidation and GSH reduced levels when compared with the control. However, supplementation of curcumin and $\mathrm{COC}$ to rats significantly $(p<0.05)$ attenuated the increase in lipid peroxidation levels and restored the GSH levels (Table 2).

\section{Effects of $\mathrm{COC}$ and curcumin on hepatic trace element in rats}

Copper, iron, and zinc were significantly $(p \leq 0.005)$ increase by treating rats with copper oxychloride compared

Table 1 Effects of COC and curcumin on serum enzyme levels in rats

\begin{tabular}{lll}
\hline Rat groups & SGPT $(\mathrm{U} / \mathrm{ml})$ & SGOT $(\mathrm{U} / \mathrm{ml})$ \\
\hline Control & $25.5 \pm 2.48^{\mathrm{a}}$ & $139.54 \pm 6.47^{\mathrm{a}}$ \\
Oil & $31.64 \pm 3.8^{\mathrm{a}, \mathrm{b}}$ & $173.38 \pm 15.1^{\mathrm{a}, \mathrm{b}}$ \\
COC LD & $71.9 \pm 5.86^{\mathrm{c}, \mathrm{d}}$ & $242.50 \pm 20.6^{\mathrm{a}, \mathrm{b}, \mathrm{c}}$ \\
COC MD & $68.5 \pm 5.72^{\mathrm{c}, \mathrm{d}}$ & $315.83 \pm 16.23^{\mathrm{c}}$ \\
COC HD & $87.08 \pm 5.26^{\mathrm{d}}$ & $322.33 \pm 23.5^{\mathrm{c}}$ \\
Curcmin & $50.8 \pm 3.12^{\mathrm{a}, \mathrm{b}, \mathrm{c}}$ & $171.28 \pm 10.21^{\mathrm{a}, \mathrm{b}}$ \\
COC LD + Curcmin & $46.0 \pm 3.9^{\mathrm{a}, \mathrm{b}, \mathrm{c}}$ & $199.6 \pm 13.71^{\mathrm{a}, \mathrm{b}}$ \\
COC MD + Curcmin & $43.66 \pm 6.1^{\mathrm{b}, \mathrm{c}, \mathrm{d}}$ & $236 \pm 11.83^{\mathrm{b}, \mathrm{c}}$ \\
COC HD + Curcmin & $49.50 \pm 5.60^{\mathrm{c}, \mathrm{d}}$ & $247 \pm 14.25^{\mathrm{b}, \mathrm{c}}$ \\
\hline
\end{tabular}

Data are presented as mean \pm SE

Means within the same row carrying different superscript letters are significantly different, and the means in the rows with a common superscript letter were not significantly different (one-way ANOVA followed by Duncan's multiple range test, $p<0.05, n=6$ per group) 
Table 2 Effects of COC and curcumin on liver GSH reduced and MDA levels in rats

\begin{tabular}{lll}
\hline Group & GSH reduced $(\mu \mathrm{g} / \mathrm{mg}$ tissue) & MDA (nmol/g tissue) \\
\hline Control & $5.3 \pm 0.17^{\mathrm{a}}$ & $2.963 \pm 0.37^{\mathrm{a}}$ \\
Oil & $8.94 \pm 0.89^{\mathrm{a}}$ & $5.125 \pm 1.49^{\mathrm{a}}$ \\
COC LD & $4.40 \pm 1.4^{\mathrm{a}}$ & $7.800 \pm 0.74^{\mathrm{a}, \mathrm{b}, \mathrm{c}}$ \\
COC MD & $11.9 \pm 2.03^{\mathrm{a}}$ & $11.900 \pm 3.41^{\mathrm{c}, \mathrm{d}}$ \\
COC HD & $10.258 \pm 5.4^{\mathrm{a}}$ & $13.44 \pm 0.96^{\mathrm{d}}$ \\
Curcmin & $14.043 \pm 1.84^{\mathrm{a}}$ & $3.739 \pm 0.70^{\mathrm{a}}$ \\
COC LD + Curcmin & $16.50 \pm 5.9^{\mathrm{b}}$ & $6.395 \pm 1.76^{\mathrm{a}, \mathrm{b}}$ \\
COC MD + Curcmin & $11.492 \pm 1.44^{\mathrm{a}}$ & $10.30 \pm 2.74^{\mathrm{b}, \mathrm{c}, \mathrm{d}}$ \\
COC HD + Curcmin & $14.66 \pm 3.20^{\mathrm{a}}$ & $11.769 \pm 2.19^{\mathrm{c}, \mathrm{d}}$ \\
\hline
\end{tabular}

Data are presented as mean \pm SE. Means within the same row carrying different superscript letters are significantly different, and the means in the rows with a common superscript letter were not significantly different (oneway ANOVA followed by Duncan's multiple range test, $p<0.05, n=6$ per group)

to the control rat (Table 3). Rat treated with curcumin and COC decrease the copper content compared to the treating groups with COC only but non-significant compared to the control group. Rat treated with curcumin and COC significantly decrease the iron and zinc content and significantly increase the manganese content compared to the control group.

\section{Histopathological results of liver}

The liver of control rat showed no marked differences with the normal structural organization of the hepatic lobules with normal polygonal hepatocytes containing central oval-shaped nuclei surrounded the central vein (Fig. 1a). Additionally, no detectable histological differences were observed between the livers of control rats and rats supplemented with corn oil and/or curcumin extract $(80 \mathrm{mg} / \mathrm{kg}$ body weight) treatment for 90 days. They preserved the liver parenchyma with the appearance of the hepatocytes; sinusoids and Kupffer cells were similar to the control histomorphology (Fig. 1c, d, respectively). The hepatocytes were arranged in strands alternating with blood sinusoid lined with endothelial and Kupffer cells forming a network around the central vein (Fig. 2a).

The liver of a rat treated for 500, 1000, and $2000 \mathrm{mg} /$ $\mathrm{kg}$ body weight $\mathrm{COC}$ for 90 days (Fig. 2) showed congestion of the central and portal veins, hydraulic degenerating of hepatocytes, necrotic lesions, the pyknotic nucleus in addition to infiltration of inflammatory cells in the COC-treated groups. The histopathological changes of the liver were obliviously increased with treatment $2000 \mathrm{mg} / \mathrm{kg}$ body weight COC, and the liver cells were degenerated and suffered from mild fatty infiltrations. Concurrent treatment with curcumin extract attenuated the extent and severity of the histological features of liver damage induced by $\mathrm{COC}$ alone. Animals treated with curcumin and COC $500 \mathrm{mg} / \mathrm{kg}$ for 90 days revealed that the majority of these histopathological changes were diminished, and the liver tissue restored most of its normal structure. Rats treated with curcumin and COC 1000 and $2000 \mathrm{mg} / \mathrm{kg}$ for 90 days, respectively, reduced necrosis, but some of the intra-hepatic vessels (the central and portal vessels) were still congested and some hepatocytes appeared with vacuolized cytoplasm involved with the dissolution and degeneration of hepatic cords with necrotic nuclei, which were the most pronounced pathological abnormalities observed. Several of the hepatocytes were fused together forming degenerated areas of destroying cells that lost their normal characters, and Kupffer cells were increased. The repairing effects-up were in the curcumin and COC for 90 days treated group were to certain limits; the hepatic lobules showed normal centrilobular hepatocytes with slightly dilated hepatic sinusoids and mild vacuolar degeneration of the adjacent hepatocytes. Also, few cells still appeared with cytoplasmic vacuolization and pyknotic nuclei with a reduction in inflammation. Rat treated with curcumin and $500 \mathrm{mg} / \mathrm{kg}$ $\mathrm{COC}$ for 90 days exhibited the appearance of giant multinucleated hepatocytes.

Table 3 Effects of COC and curcumin on hepatic trace element in rats

\begin{tabular}{|c|c|c|c|c|}
\hline Group & Copper $(\mu \mathrm{g} / \mathrm{dL})$ & Iron $(\mu \mathrm{g} / \mathrm{dL})$ & Manganese $(\mu \mathrm{g} / \mathrm{dL})$ & $\overline{\operatorname{Zinc}(\mu \mathrm{g} / \mathrm{dL})}$ \\
\hline Control & $0.137 \pm 0.00^{a}$ & $3.61 \pm 0.00^{c}$ & $0.08 \pm 0.00^{\mathrm{a}}$ & $3.61 \pm 0.00^{c}$ \\
\hline Oil & $0.230 \pm 0.01^{\mathrm{a}}$ & $4.53 \pm 0.18^{d}$ & $0.17 \pm 0.01^{a}$ & $4.53 \pm 0.18^{a}$ \\
\hline COC LD & $38.07 \pm 0.00^{d}$ & $1.73 \pm 0.00^{\mathrm{a}}$ & $1.37 \pm 0.26^{b}$ & $1.78 \pm 0.00^{d}$ \\
\hline $\mathrm{COC} M D$ & $46.35 \pm 1.2^{f}$ & $3.72 \pm 0.36^{c}$ & $0.28 \pm 0.1^{a}$ & $3.72 \pm 0.36^{e}$ \\
\hline $\mathrm{COCHD}$ & $54.62 \pm 0.00^{g}$ & $5.56 \pm 0.00^{\mathrm{e}}$ & $0.15 \pm 0.00^{\mathrm{a}}$ & $5.65 \pm 0.00^{f}$ \\
\hline Curcmin & $0.248 \pm 0.04^{\mathrm{a}}$ & $4.71 \pm 0.40^{c, d}$ & $0.09 \pm 0.03^{a}$ & $4.71 \pm 0.40^{a}$ \\
\hline COC LD + Curcmin & $18.15 \pm 0.00^{b}$ & $2.30 \pm 0.00^{a, b}$ & $2.97 \pm 0.00^{c}$ & $2.30 \pm 0.00^{c}$ \\
\hline $\mathrm{COC} \mathrm{MD}+$ Curcmin & $43.46 \pm 0.00^{€}$ & $3.31 \pm 0.00^{c}$ & $5.95 \pm 0.00^{d}$ & $3.31 \pm 0.00^{b, c}$ \\
\hline $\mathrm{COC} \mathrm{HD}+$ Curcmin & $26.55 \pm 0.04^{c}$ & $2.55 \pm 0.00^{b}$ & $3.05 \pm 0.00^{c}$ & $2.55 \pm 0.00^{\mathrm{a}, \mathrm{b}}$ \\
\hline
\end{tabular}

Data are presented as mean \pm SE. Means within the same row carrying different superscript letters are significantly different, and the means in the rows with a common superscript letter were not significantly different (one-way ANOVA followed by Duncan's multiple range test $p<0.05, n=6$ per group) 

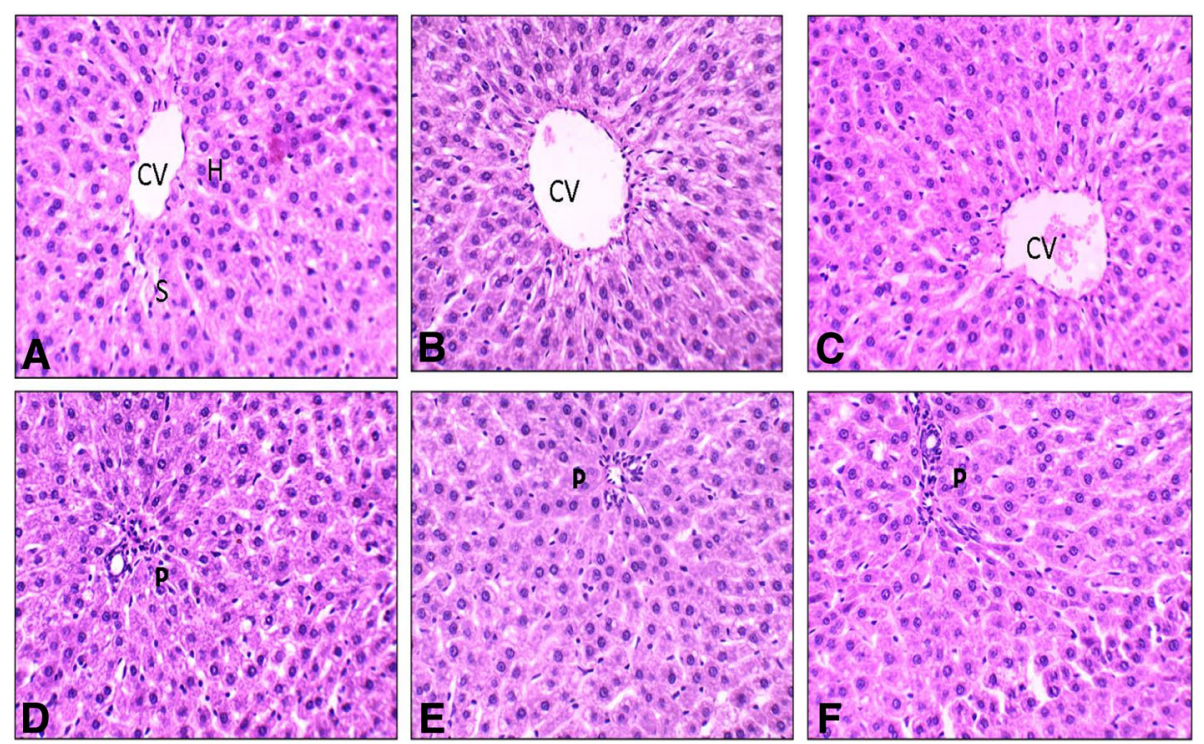

Fig. 1 a Liver section of a control rat showing hepatic cell $(\mathrm{H})$, central vein $(\mathrm{CV})$, and hepatic sinusoid $(\mathrm{S})$ with Kupffer cell. b Liver section of a rat treated with corn oil showing normal hepatic cell surrounding the central vein (CV). $\mathbf{c}$ Liver section of a rat treated with curcumin extract showing normal hepatic cell surrounding the central vein (CV). $\mathbf{d}$ Liver section of a control rat showing the normal histological appearance of the portal area (P). e Liver section of a rat treated with corn oil showing the normal histological appearance of the portal area (P). $\mathbf{f}$ Liver section of a rat treated with curcumin extract showing the normal histological appearance of the portal area (P). (H\&E stain, $\times 400)$
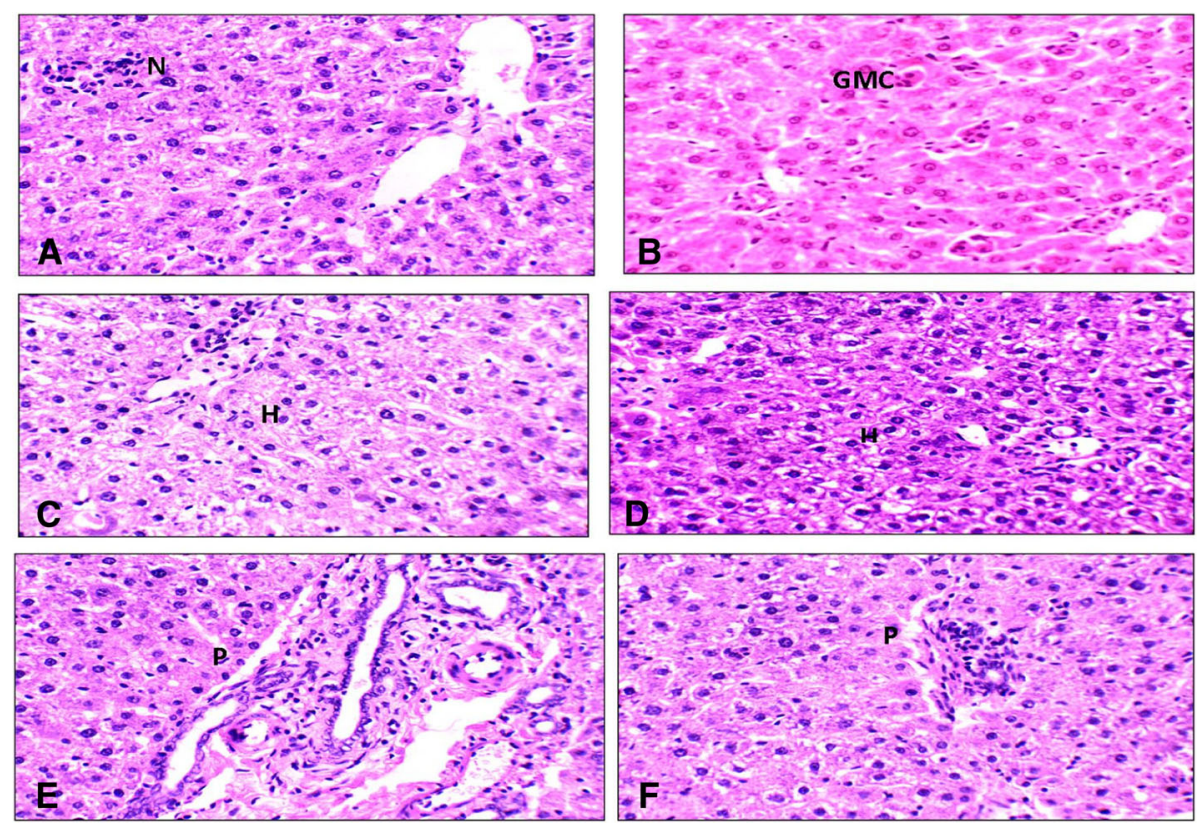

Fig. 2 a Section of liver from a rat treated with $500 \mathrm{mg} / \mathrm{kg}$ body weight COC for 90 days showing congestion of central vein (CV) and cytoplasmic vacuolization of the hepatocytes (arrows), $\times 400$. b Liver section obtained from a rat treated with $500 \mathrm{mg} / \mathrm{kg}$ COC; the restoration of the normal arrangement of the hepatocytes and giant multinucleate cells (GMC). c Section of liver from a rat treated with $1000 \mathrm{mg} / \mathrm{kg}$ body weight COC for 90 days showing hydrobic degeneration $(H)$ appeared as cytoplasmic vacuolization of the hepatocytes and increase of pyknotic cells. $\mathbf{d}$ Section of liver from a rat treated with $1000 \mathrm{mg} / \mathrm{kg}$ body weight COC and curcumin for 3 months showing hydrobic degeneration (H) appeared as cytoplasmic vacuolization of the hepatocytes and absence of pyknotic cells. e Liver section of a rat examined after 90 days of treatment with $2000 \mathrm{mg} / \mathrm{kg}$ body weight COC shows a large mass of inflammatory infiltration in the portal area (P). $\mathbf{f}$ Liver section obtained from a rat treated with $2000 \mathrm{mg} / \mathrm{kg}$ body weight COC followed with curcumin extract for 90 days showing improvement of hepatic tissue and decreasing the mass of inflammatory infiltration in the portal area (P), H\&E, $\times 400$ 
The histochemical staining of liver

For revealing the deposition of collagen fibers, the liver sections were stained with Masson's trichrome. Collagen fibers were stained blue by the Masson's trichrome; the increase of collagen fibers was absent in the liver of COC-treated rats around the central vein and in the blood sinusoids even the congestion portal vein and bile duct compared to the control and curcumin group (Fig. 3).

\section{The immunohistochemical staining of the liver}

Qualitative evaluation showed focal caspase 3 reactions in the slides prepared from control and experimental animals (Fig. 4). The color reaction was bright, pale pink and filled evenly the whole hepatocyte cytoplasm. Weak-intensive reaction was found in the COC-treated group. The intensity of the positive reaction was almost the same in the control and treated curcumin with COC groups.

\section{Ultrastructure changes in rat liver}

The ultrastructural examination of the liver sections of the control group Fig. 5 exhibited ideal hepatocytes with normally round nucleus with evenly distributed chromatin, sometimes slightly condensed along the nuclear membrane in hepatocytes; the nucleus is easily distinguished with numerous round, oval, elongated rod-like mitochondria with membranous cristae and electron dense matrix. The normal rough endoplasmic reticulum
(RER) and the smooth endoplasmic reticulum (SER) occurred in glycogen-rich areas.

The ultrastructure of a hepatocyte of the liver after curcumin treatment $80 \mathrm{mg} / \mathrm{kg}$ body weight for 90 days did not show any changes comparing to the ultrastructure of hepatocytes of the control. In contrast, the hepatocytes of the liver sections from the group treated with $500 \mathrm{mg} / \mathrm{kg}$ body weight COC Fig. 6a showed ultrastructure alteration, including irregularity and degenerative changes in the nuclear membrane. Shrunken and pyknotic nuclei in the degenerated hepatocyte were seen. The cytoplasm was condensed and contained degenerative changes such as condensed, atrophied, and damaged mitochondria with no cristae, in the majority of mitochondria. Also, the intra-mitochondrial granules disappeared; varieties of mitochondria were small, large, branching, and budding; and the RER was decreased in amount. Dilated intercellular spaces were observed between hepatocytes. Early phases of apoptosis and atrophic nuclei were also detected. Disrupted RER and numerous different sizes lysosome were also seen. Cytoplasmic vacuolization and dilated bile canaliculi with damage and atrophy of its microvilli as well as swollen and damaged Kupffer cell with irregular nuclear membrane were also observed. The hepatocytes of the liver sections from the group treated with $2000 \mathrm{mg} / \mathrm{kg}$ body weight COC (Fig. 6a) showed severe cytoplasmic vacuolization and cristae loss in mitochondria; some shape varieties of mitochondria are small, large, branching, and
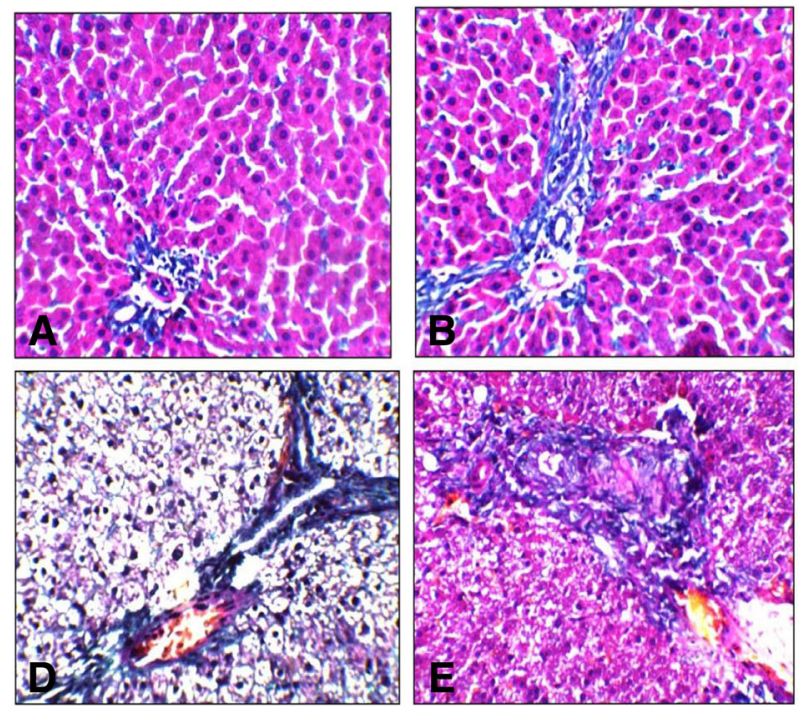

Fig. 3 a A section in the liver of control rats showing normal distribution of collagen fibers and fibrils, normal hepatocytes, normal blood sinusoids, and portal area. $\mathbf{b}$ A section in the liver of treated rats with curcumin extract showing normal distribution of collagen fibers. $\mathbf{c}$, $\mathbf{d}$ A section in the liver of 500 and $2000 \mathrm{mg} / \mathrm{kg}$ COC-treated rat showing degenerated hepatocytes with deposition of collagen fibers around the central vein and in the dilated blood sinusoids. e A section in the liver of $2000 \mathrm{mg} / \mathrm{kg}$ COC- and curcumin-treated rat showing branches of the hepatic portal vein, hepatic artery, and bile duct with marked deposition of collagen fibers surrounding them. $\mathbf{f}$ A section in the liver of $500 \mathrm{mg} /$ $\mathrm{kg} \mathrm{COC}$ - and curcumin-treated rat showing branches of the hepatic portal vein, hepatic artery, and bile duct with mild deposition of collagen fibers surrounding them (Masson's trichrome $\times 400$ ) 

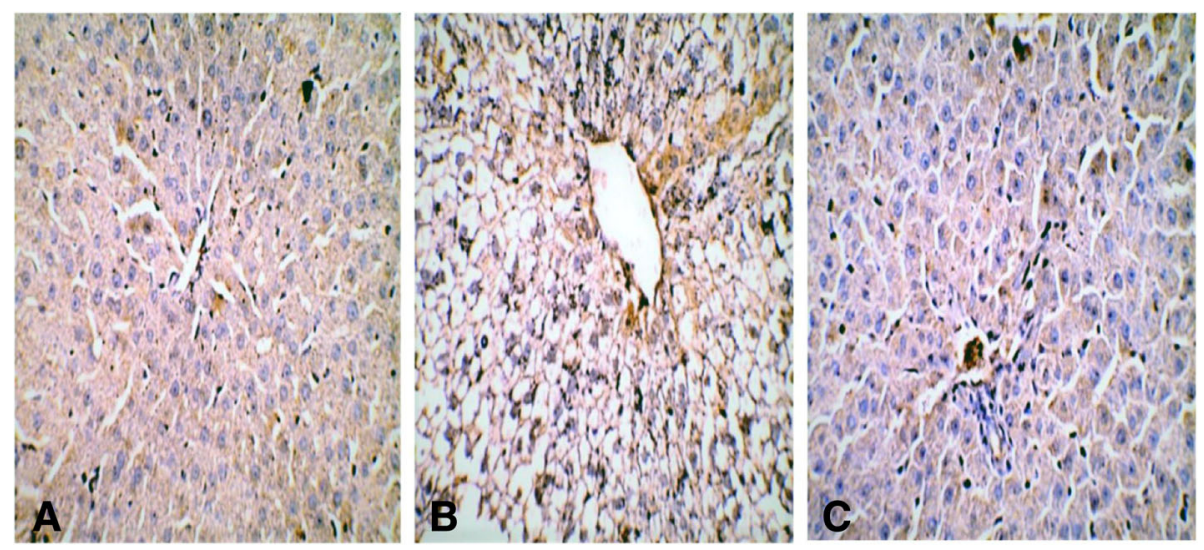

Fig. 4 Expression of caspase 3 immunohistochemical staining $(\times 400)$. a A section obtained from the liver of a control rat shows caspase 3immunolabeled hepatocytes were rarely present. b A section obtained from the liver of a rat treated with $500 \mathrm{mg} / \mathrm{kg}$ COC shows a decreased number of caspase 3-immunolabeled hepatocytes were observed around central veins, identified by brown staining. c Sections taken from the liver of a rat treated with curcumin followed by $500 \mathrm{mg} / \mathrm{kg}$ COC shows caspase 3-immunolabeled cells were slightly similar to the control group

budding; and collagen fiber deposition and other degenerative changes were observed. However, curcumin with the COC (Fig. 6b, d) showed markedly attenuated remarkable improvement from the COC-treated group; most of the hepatocytes nuclei, cytoplasmic organelles, intercellular space, bile canaliculi, and Kupffer cells were more or less normal. The mitochondrial matrix recovered its density, and intra-mitochondrial granules gradually appeared, but there were still recognized a few mitochondria without granules, and most of the organelles appeared in a healthier appearance.

\section{Discussion}

The present investigation was suggested to explore the precise long-term toxic effects of COC fungicide exposure in male rats. The results of this study indicated that treatment of rats with $\mathrm{COC}$ caused significant alterations

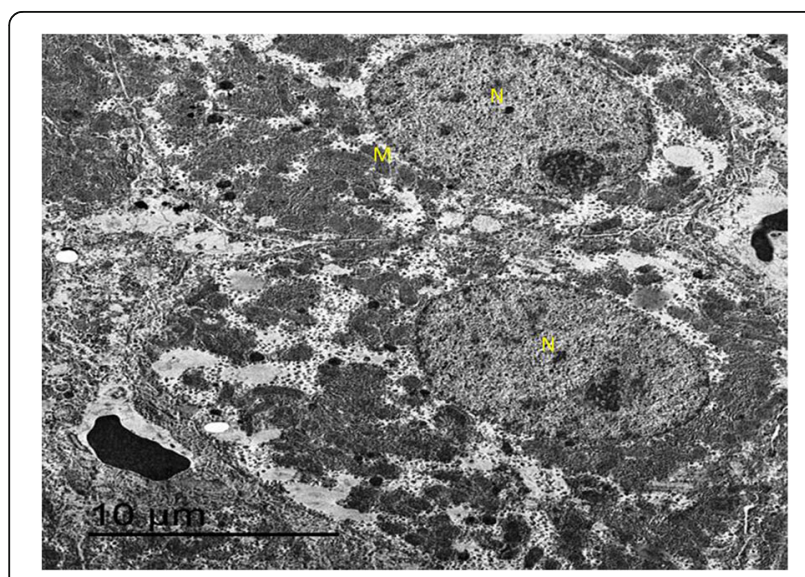

Fig. 5 (A) An electron micrograph of control rat liver showing a hepatocyte with an active nucleus (N) with nucleoli, and rich in mitochondria (M); glycogen is also seen in the liver enzymes SGPT and SGOT activities which are known marker enzymes for the assessment of the functional integrity of the liver cells (Cohen and Kaplan 1979). These enzymes are usually raised in acute hepatotoxicity or mild hepatocellular injury or extrahepatic obstruction (Thapa and Walia 2007) but tend to decrease with prolonged intoxication due to damage to the liver (Cohen and Kaplan 1979). In this study, the activities of serum SGPT and SGOT were significantly increased in the COC groups. On the other hand, curcumin administration to rats treated with $\mathrm{COC}$ produced an appreciable improvement in the hepatotoxic effect by the reversal of 500 and $1000 \mathrm{mg} / \mathrm{kg}$ body weight Also, the curcumin group and oil group produced a non-significant increase to the SGPT and SGOT levels. The recorded changes in these biochemical parameters were substantiated by the histopathological changes. The present work displayed hepatocellular damage as a dose-dependent lesion. The rise in serum SGPT and SGOT activities may be a result of the sudden change in tissue permeability, cell fragmentation, or from a specific phase of progressive cellular damage (McIntyre 2004).

Copper oxychloride caused an increase content of MDA in the liver as a measure of lipid peroxidation, which accompanied by damage of hepatocytes and no relevant effect to the GSH concentration compared to those of controls. The increase content of MDA in the liver may be due to the increase of copper content in the liver, and the absence of change in the glutathione-reduced content in the liver is not in agreement to other studies, which found the depletion of hepatic glutathione content resulting from copper increase (Ozcelik et al. 2003)

Treatment of curcumin, along with $\mathrm{COC}$ treatment, decreased the COC-induced changes in hepatic lipid peroxidation and restore glutathione-reduced levels. The observed protective activities of curcumin extract against 

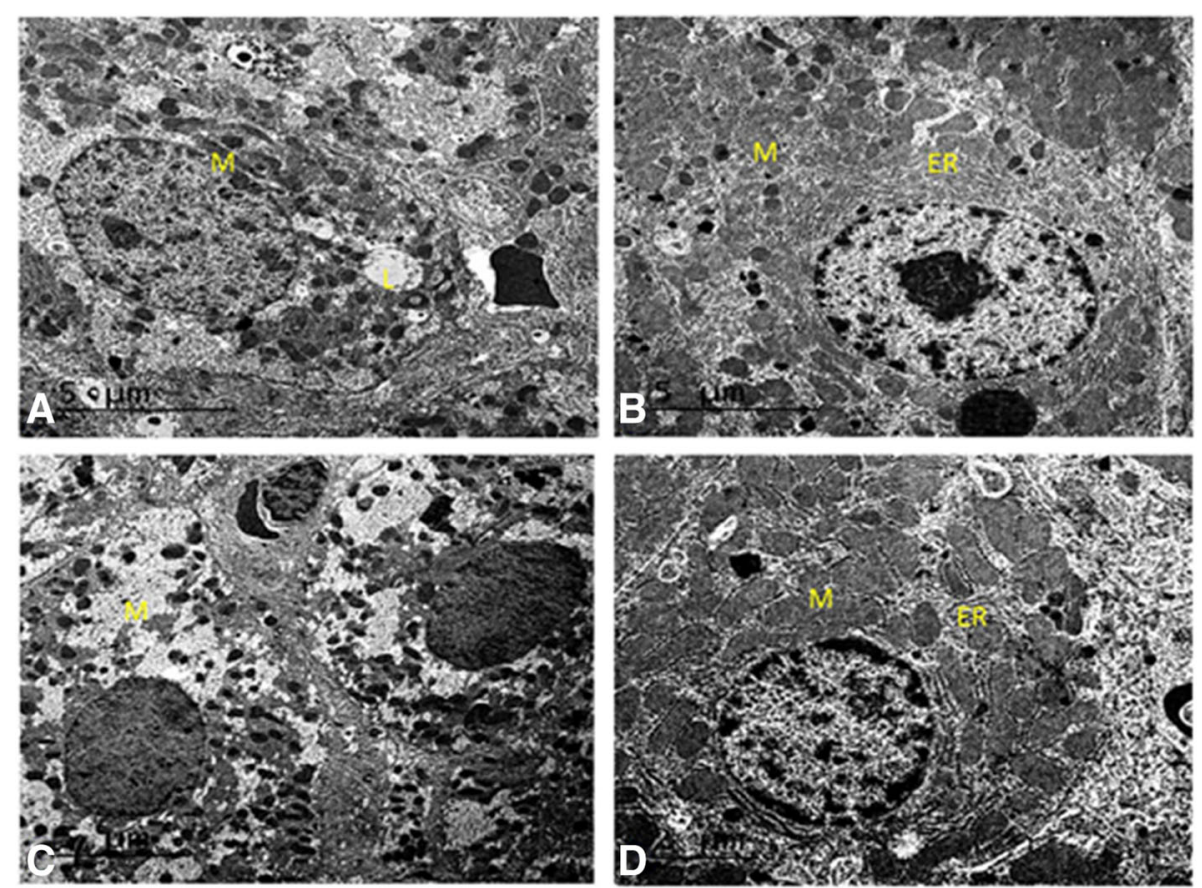

Fig. 6 a An electron micrograph of $500 \mathrm{mg} / \mathrm{kg}$ body weight COC-treated rat liver for 90 days showing necrotic liver cell with the nuclear chromatin beginning of losing and losing mitochondria and elongating of some mitochondria (M), mild dissolution of the cytoplasm, and appearing of lipid droplets (L). b An electron micrograph of $500 \mathrm{mg} / \mathrm{kg}$ body weight COC- and curcumin $80 \mathrm{mg} / \mathrm{kg}$-treated rat liver for 90 days showing normal hepatocyte with increasing number of mitochondria (M) and rough endoplamic reticulum (ER). c An electron micrograph of $2000 \mathrm{mg} / \mathrm{kg}$ body weightCOC-treated rat liver for 90 days showing a dissolution of the cytoplasm with degeneration to most organs of cytoplasm and mitochondria (M), an abnormal nucleus with loss of chromatin. d An electron micrograph of 2000 mg/kg body weight COC- and curcumin 80 mg/kg-treated rat liver for 90 days showing normal hepatocyte with increasing number of mitochondria (M) and rough endoplamic reticulum (ER)

COC-induced hepatotoxicity could be attributed to the various anti-oxidant compounds present in the extract (Madsen and Bertelsen 1995) which reduce the lipid peroxidation and stabilize to an extent the liver cell membrane, and that result is in agreement to previous studies of curcumin as hepatoprotective to different liver toxicity treatment (Farombi et al. 2008; García-Niño and Pedraza-Chaverrí 2014; Girish et al. 2009; Girish and Pradhan 2012; Singh and Sharma 2011).

Copper, iron, and zinc were significantly increased by treating rats with $\mathrm{COC}$, and this is due to the interaction of the absorption of these trace elements with each other (Chin et al. 2014). The significant increase of zinc with the increase of copper is not similar to the studies of Abdulla and Chmielnicka (1989) that showed treatment with zinc induce copper deficiency. Rat treated with curcumin and COC decrease the copper content compared to the treating groups with $\mathrm{COC}$ only but non-significant compared to the control group. Rat treated with curcumin and COC significantly decrease the iron and zinc content and significantly increase the manganese content compared to the control group, and these are due to the action of curcumin as a chelating agent for iron, copper, and zinc (Baum and Ng 2004; Chin et al. 2014). The oil group showed a significant increase to the iron and zinc liver content due to its content of trace amounts of metals, which may be from mineral uptake from the soil or from the agrochemicals compound or metal contamination from using metal equipment in the production processes, storage, and transportation (Nnorom and Ewuzie 2015).

Histological alterations of COC shown within the present investigation are nearly identical as compared to those seen with the findings of others exposure to copper. The histologic changes of hepatic tissues showed congestion of the central vein and portal triad vessels and these agreements to Doudi and Setorki (2014) that found histopathological changes in liver induced by the nanoparticles of copper. The appearance of inflammatory cells within the hepatic tissue could also be because of the interaction of copper with proteins and enzymes of the hepatic interstitial tissue with antioxidant defense mechanism which can result in generating the reactive oxygen species (ROS) that sucessively initiate the inflammatory response (Fubini and Hubbard 2003). The results of the current work showed that COC exposure damages the hepatocytes with cytoplasmic inclusions and may be due to the unable to upset with the accumulated 
residues from metabolic and structural disturbances caused by copper.

The cytoplasmic swelling with hydropic degeneration as observed within the results of the current investigation might result from the leakage of lysosomal hydrolytic enzymes that lead to cytoplasmic degeneration (Del Monte 2005). COC caused caspase 3 inhibition which confirmed the necrotic effect (Coelho et al. 2000) of these antifungal pesticides to the liver tissue.

The present results showed that treating rats with COC and curcumin improved and ameliorated the biochemical changes and confirmed by histopathological and cellular observations.

\section{Conclusion}

Exposure to the fungicide COC could potentially harm human health, which provides evidence of hepatotoxicity. The fungicide induced significant alterations in the hepatic function and an increase of hepatic lipid peroxidation in rats with a consequent histopathological and cellular damage. The results set up the possibility of curcumin being considered as one of the components of the regular diet of people to protect and reduce most of the hepatic damage caused by fungicide $\mathrm{COC}$ in the liver. The mechanism appeared mostly to be mediated by counteracting free radical reduction generated by COC.

\section{Abbreviations}

COC HD: Copper oxychloride 2000; COC LD: Copper oxychloride 500; COC MD: Copper oxychloride 1000; COC: Copper oxychloride; CU: Curcumin; CV: Central vein; GSH: Hepatic glutathione reduced content; MDA: Malondialdehyde; S: Hepatic sinusoid; SGOT: Serum glutamic-oxaloacetic transaminase; SGPT: Serum glutamic-pyruvic transaminase

\section{Acknowledgements}

Not applicable.

\section{Funding}

Not applicable.

\section{Availability of data and materials}

The datasets generated and analyzed during the current study is available from the corresponding author on reasonable request.

\section{Authors' contributions}

Both authors proposed the study and contributed to the design and interpretation of the study. Both authors read and approved the final manuscript.

\section{Ethics approval and consent to participate}

This study was carried out and approved in accordance with the ethical rules for handling the experimental animals, Zoology Department, Faculty of Science, Suez Canal University, Ismailia, Egypt.

\section{Consent for publication}

Not applicable.

\section{Competing interests}

The authors declare that they have no competing interests.

\section{Publisher's Note}

Springer Nature remains neutral with regard to jurisdictional claims in published maps and institutional affiliations.

Received: 2 May 2018 Accepted: 21 October 2018

Published online: 03 November 2018

\section{References}

Abdulla, M., \& Chmielnicka, J. (1989). New aspects on the distribution and metabolism of essential trace elements after dietary exposure to toxic metals. Biological Trace Element Research, 23, 25-53.

Baum, L., \& Ng, A. (2004). Curcumin interaction with copper and iron suggests one possible mechanism of action in Alzheimer's disease animal models. Journal of Alzheimer's Disease, 6, 367-377.

Bruck, R., Ashkenazi, M., Weiss, S., Goldiner, I., Shapiro, H., Aeed, H., ... Pines, M. (2007). Prevention of liver cirrhosis in rats by curcumin. Liver International, 27, 373-383.

Chin, D., Huebbe, P., Frank, J., Rimbach, G., \& Pallauf, K. (2014). Curcumin may impair iron status when fed to mice for six months. Redox Biology, 2. 563-569.

Coelho, D., Holl, V., Weltin, D., Lacornerie, T., Magnenet, P., Dufour, P., \& Bischoff, P. (2000). Caspase-3-like activity determines the type of cell death following ionizing radiation in MOLT-4 human leukaemia cells. British Journal of Cancer, $83,642$.

Cohen, J. A., \& Kaplan, M. M. (1979). The SGOT/SGPT ratio—an indicator of alcoholic liver disease. Digestive Diseases and Sciences, 24, 835-838.

Council, N.R (2010). Guide for the care and use of laboratory animals. National Academies Press.

Damalas, C. A., \& Eleftherohorinos, I. G. (2011). Pesticide exposure, safety issues, and risk assessment indicators. International Journal of Environmental Research and Public Health, 8, 1402-1419.

Del Monte, U. (2005). Swelling of hepatocytes injured by oxidative stress suggests pathological changes related to macromolecular crowding. Medical Hypotheses, 64, 818-825.

Doudi, M., \& Setorki, M. (2014). Acute effect of nano-copper on liver tissue and function in rat. Nanomedicine Journal, 1.

Farombi, E. O., Shrotriya, S., Na, H.-K., Kim, S.-H., \& Surh, Y.-J. (2008). Curcumin attenuates dimethylnitrosamine-induced liver injury in rats through Nrf2mediated induction of heme oxygenase-1. Food and Chemical Toxicology, 46, 1279-1287.

Fischer, A.H., Jacobson, K.A., Rose, J., Zeller, R., 2008. Hematoxylin and eosin staining of tissue and cell sections. Cold Spring Harbor Protocols 2008, pdb. prot4986.

Fu, Y., Zheng, S., Lin, J., Ryerse, J., \& Chen, A. (2008). Curcumin protects the rat liver from CCl4-caused injury and fibrogenesis by attenuating oxidative stress and suppressing inflammation. Molecular Pharmacology, 73, 399-409.

Fubini, B., \& Hubbard, A. (2003). Reactive oxygen species (ROS) and reactive nitrogen species (RNS) generation by silica in inflammation and fibrosis. Free Radical Biology and Medicine, 34, 1507-1516.

Gao, S., Duan, X., Wang, X., Dong, D., Liu, D., Li, X., ... Li, B. (2013). Curcumin attenuates arsenic-induced hepatic injuries and oxidative stress in experimental mice through activation of Nrf2 pathway, promotion of arsenic methylation and urinary excretion. Food and Chemical Toxicology, $59,739-747$

García-Niño, W. R., \& Pedraza-Chaverrí, J. (2014). Protective effect of curcumin against heavy metals-induced liver damage. Food and Chemical Toxicology, 69, 182-201.

Gebhardt, R. (1992). Metabolic zonation of the liver: regulation and implications for liver function. Pharmacology \& Therapeutics, 53, 275-354.

Girish, C., Koner, B. C., Jayanthi, S., Ramachandra Rao, K., Rajesh, B., \& Pradhan, S. C. (2009). Hepatoprotective activity of picroliv, curcumin and ellagic acid compared to silymarin on paracetamol induced liver toxicity in mice. Fundamental \& Clinical Pharmacology, 23, 735-745.

Girish, C., \& Pradhan, S. (2012). Hepatoprotective activities of picroliv, curcumin, and ellagic acid compared to silymarin on carbon-tetrachloride-induced liver toxicity in mice. Journal of pharmacology \& pharmacotherapeutics, 3, 149.

Goldner, J. (1938). A modification of the Masson trichrome technique for routine laboratory purposes. The American Journal of Pathology, 14, 237.

Hashish, E. A., \& Elgaml, S. A. (2016). Hepatoprotective and nephroprotective effect of curcumin against copper toxicity in rats. Indian Journal of Clinical Biochemistry, 31, 270-277. 
Hissin, P. J., \& Hilf, R. (1976). A fluorometric method for determination of oxidized and reduced glutathione in tissues. Analytical Biochemistry, 74, 214-226.

Hui, Y.-h., Huang, N. H., Ebbert, L., Bina, H., Chiang, A., Maples, C., ... Patel, N. (2007). Pharmacokinetic comparisons of tail-bleeding with cannula-or retroorbital bleeding techniques in rats using six marketed drugs. Journal of Pharmacological and Toxicological Methods, 56, 256-264.

Husak, V. (2015). Copper and copper-containing pesticides: metabolism, toxicity and oxidative stress. Journal of Vasyl Stefanyk Precarpathian National University, 39-51.

Joe, B., Vijaykumar, M., \& Lokesh, B. (2004). Biological properties of curcumincellular and molecular mechanisms of action. Critical Reviews in Food Science and Nutrition, 44, 97-111.

Jovanovic, S. V., Steenken, S., Boone, C. W., \& Simic, M. G. (1999). H-atom transfer is a preferred antioxidant mechanism of curcumin. Journal of the American Chemical Society, 121, 9677-9681.

Key, M., 2006. Immunohistochemistry staining methods. Education Guide Immunohistochemical Staining Methods Fourth Edition, 47.

Kim, K.-H., Kabir, E., \& Jahan, S. A. (2017). Exposure to pesticides and the associated human health effects. Science of the Total Environment, 575, 525-535.

Luterotti, S., \& Juretić, D. (1992). Rapid and simple method for the determination of copper, manganese and zinc in rat liver by direct flame atomic absorption spectrometry. Analyst, 117, 141-143.

Madsen, H. L., \& Bertelsen, G. (1995). Spices as antioxidants. Trends in Food Science \& Technology, 6, 271-277.

Manjunatha, H., \& Srinivasan, K. (2006). Protective effect of dietary curcumin and capsaicin on induced oxidation of low-density lipoprotein, iron-induced hepatotoxicity and carrageenan-induced inflammation in experimental rats. The FEBS Journal, 273, 4528-4537.

McIntyre, N. (2004). 11. Clinical biochemistry of the liver. Principles of Medical Biology, 15, 291-316.

Naik, R., Mujumdar, A., \& Ghaskadbi, S. (2004). Protection of liver cells from ethanol cytotoxicity by curcumin in liver slice culture in vitro. Journal of Ethnopharmacology, 95, 31-37.

Naik, S. R., Thakare, V. N., \& Patil, S. R. (2011). Protective effect of curcumin on experimentally induced inflammation, hepatotoxicity and cardiotoxicity in rats: evidence of its antioxidant property. Experimental and Toxicologic Pathology, 63, 419-431.

Nanji, A. A., Jokelainen, K., Tipoe, G. L., Rahemtulla, A., Thomas, P., \& Dannenberg, A. J. (2003). Curcumin prevents alcohol-induced liver disease in rats by inhibiting the expression of NF-kB-dependent genes. American Journal of Physiology-Gastrointestinal and Liver Physiology, 284, G321-G327.

Nnorom, I. C., \& Ewuzie, U. (2015). Comparative study of trace metal $(\mathrm{Cd}, \mathrm{Cr}$, Cu, $\mathrm{Fe}, \mathrm{K}, \mathrm{Mg}, \mathrm{Na}$, and Zn). Asian J Plant Sci Res, 5, 22-29.

Ohkawa, H., Ohishi, N., \& Yagi, K. (1979). Assay for lipid peroxides in animal tissues by thiobarbituric acid reaction. Analytical Biochemistry, 95, 351-358.

Olfert, E.D., Cross, B.M., McWilliam, A.A., 1993. Guide to the care and use of experimental animals. Canadian Council on Animal Care Ottawa.

Osman, A. H., El-Shama, S. S., Osman, A. S., \& Elhameed, A. K. A. (2011). Toxicological and pathological evaluation of prolonged bromuconazole fungicide exposure in male rats. The Medical Journal of Cairo University, 79.

Otuechere, C.A., Abarikwu, S.O., Olateju, V.I., Animashaun, A.L., Kale, O.E., 2014. Protective effect of curcumin against the liver toxicity caused by propanil in rats. International scholarly research notices 2014.

Ozcelik, D., Ozaras, R., Gurel, Z., Uzun, H., \& Aydin, S. (2003). Copper-mediated oxidative stress in rat liver. Biological Trace Element Research, 96, 209-215.

Park, E. J., Jeon, C. H., Ko, G., Kim, J., \& Sohn, D. H. (2000). Protective effect of curcumin in rat liver injury induced by carbon tetrachloride. Journal of Pharmacy and Pharmacology, 52, 437-440.

Priyadarsini, K. I. (1997). Free radical reactions of curcumin in membrane models. Free Radical Biology and Medicine, 23, 838-843.

Reddy, A. C. P., \& Lokesh, B. (1996). Effect of curcumin and eugenol on ironinduced hepatic toxicity in rats. Toxicology, 107, 39-45.

Reitman, S., \& Frankel, S. (1957). A colorimetric method for the determination of serum glutamic oxalacetic and glutamic pyruvic transaminases. American Journal of Clinical Pathology, 28, 56-63.

Saleem, U., Amin, S., Ahmad, B., Azeem, H., Anwar, F., \& Mary, S. (2017). Acute ora toxicity evaluation of aqueous ethanolic extract of Saccharum munja Roxb. roots in albino mice as per OECD 425 TG. Toxicology Reports, 4, 580-585.
Sato, S., Adachi, A., Sasaki, Y., \& Ghazizadeh, M. (2008). Oolong tea extract as a substitute for uranyl acetate in staining of ultrathin sections. Journal of Microscopy, 229, 17-20.

Shen, S.-Q., Zhang, Y., Xiang, J.-J., \& Xiong, C.-L. (2007). Protective effect of curcumin against liver warm ischemia/reperfusion injury in rat model is associated with regulation of heat shock protein and antioxidant enzymes. World journal of gastroenterology: WJG, 13, 1953.

Singh, R., \& Sharma, P. (2011). Hepatoprotective effect of curcumin on lindaneinduced oxidative stress in male Wistar rats. Toxicology International, 18, 124

Thapa, B., \& Walia, A. (2007). Liver function tests and their interpretation. The Indian Journal of Pediatrics, 74, 663-671.

Wu, G. (2009). Amino acids: metabolism, functions and nutrition. Amino acids, 37, 1-17.

Yousef, M. I., Omar, S. A., El-Guendi, M. I., \& Abdelmegid, L. A. (2010). Potential protective effects of quercetin and curcumin on paracetamol-induced histological changes, oxidative stress, impaired liver and kidney functions and haematotoxicity in rat. Food and Chemical Toxicology, 48, 3246-3261.

\section{Submit your manuscript to a SpringerOpen ${ }^{\mathcal{O}}$ journal and benefit from:}

- Convenient online submission

- Rigorous peer review

- Open access: articles freely available online

- High visibility within the field

- Retaining the copyright to your article

Submit your next manuscript at $\boldsymbol{\nabla}$ springeropen.com 